\title{
Embedment properties of Japanese cedar (Cryptomeria japonica) treated with resin impregnation
}

Keita Ogawa ${ }^{1 *}$, Satoshi Fukuta² and Kenji Kobayashi ${ }^{1}$

\begin{abstract}
To strengthen the embedment properties of wood, this study applied the resin impregnation technique, which fills the resin into wood cells. The urethane prepolymer and acrylic monomer were selected in this study. A mechanical test by a round steel bar loaded to the wood specimen was conducted. The characteristics showed higher values in the resin-impregnated groups than in the control specimen group, especially in the stiffness. The urethane- and acryl-impregnated group showed 3.78 and 2.27 times the stiffness values of the control groups in the parallel-loaded condition, and 1.94 and 1.24 times those of the control group in the perpendicularly loaded condition, respectively. Although the stiffness was significantly increased, there was a lack of ductility, which seems to be a serious problem for construction application.
\end{abstract}

Keywords: Wood, Wood cell, Embedment property, Resin, Load-deformation relationship

\section{Introduction}

Wood is an environmentally friendly construction material [1]. With the various problems related to climate change increasing globally, the utilization of wood in construction is gaining attention. Therefore, it is expected that timber construction has to extend the building types that are generally constructed using steel or concrete. Practically, strengthening the mechanical properties of timber joints has become crucial. It is well known that joints are often the weakest points in timber structures. If a new timber joint with high mechanical performance is developed, the range covered by timber construction will become widespread in building types.

Dowel-type joints are widely used in timber construction. The embedment property of timber members is a significant factor that governs the resistance properties of the joint against lateral load. For example, the stiffness

\footnotetext{
*Correspondence: ogawa.keita@shizuoka.ac.jp

${ }^{1}$ College of Agriculture, Academic Institute, Shizuoka University, 836

Ohya, Suruga-ku, Shizuoka 422-8529, Japan

Full list of author information is available at the end of the article
}

of the joint is strongly influenced by the embedment stiffness of wood, whereas the yield load of the joint is strongly influenced by the yield load of the wood. The stiffness and yield load can be theoretically calculated using the beam theory on the elastic foundation [2] and the European yield theory [3], respectively. Therefore, it is clear that strengthening the embedment properties is effective for the development of joints with high mechanical performance.

Many researchers have attempted to strengthen the embedment properties of wood. Rodd et al. inserted densified veneer wood (DVW) to the interface surface of jointed members, so that the fastener passes through the DVW and bears it to supplement the resistance of the wood member [4]. Leijten assembled timber joints with a combined use of DVW and expanded steel tubes [5]. Some buildings have adopted these reinforced joints [6]. For example, Blass et al. used a nail plate [7], Santos et al. used ring-shaped metal and carbon fiber reinforced plastic (CFRP) [8], Lederer et al. used an oriented strand board and plywood [9], and Tang et al. mounted a steel plate with adhesion or screws [10] to reinforce the timber 
joint. Namari et al. revealed that compressed wood has a higher embedment performance than normal wood and shows the possibility of developing timber joints with high mechanical performance [11].

When the dowel-type joint is deformed by a lateral load, the wood member is embedded by the fastener. The embedment occurred near the fastener, as shown in the brown part of Fig. 1. The figure also shows a scanning electron microscope (SEM) image of the embedded part. In the upper part of the SEM image, it was found that the cells were crushed by embedment loading. Therefore, the embedment deformation of wood that occurs under lateral load is ultimately known for the crushing of wood cells, and the inhibition of the crush seems to be effective for strengthening the embedment properties of wood. The authors then focused on the resin impregnation technique developed by Fukuta et al. [12]. This technique consists of two processing stages: a microscopic incision on the wood surface is created with an ultraviolet-wavelength short-pulse laser and resin impregnation into the wood cell from the incision. The authors expected that if the wood cells were filled with resin, it would be difficult to crush the cells. An additional advantage is that it can be applied to arbitrary local areas of wood surfaces and involves minimal unnecessary treatment work.

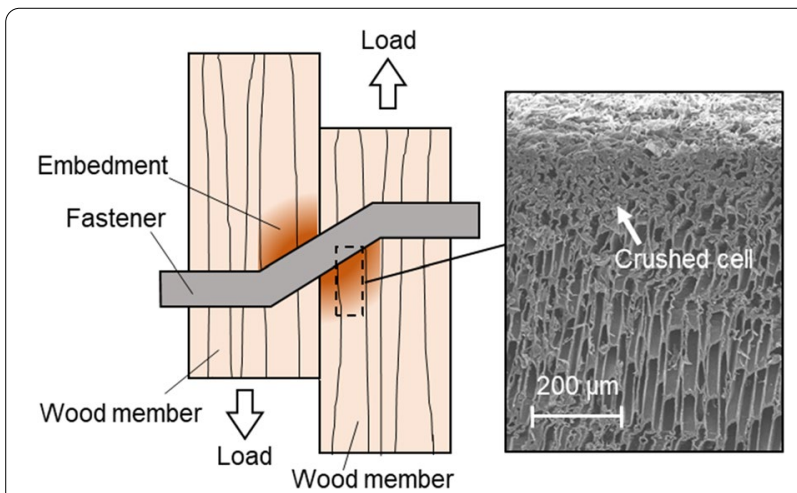

Fig. 1 Embedment deformation under lateral load acting on a dowel-type timber joint
Previously, the authors tried to apply resin impregnation to bolted joints, and significant improvements in the initial stiffness and yield load were demonstrated [13].

Our previous research revealed improvements with only limited joint specifications, and the improving effects with the other joint specification were not clear. If the embedment properties become revealed, the evaluations of lateral resisting properties of various dowel-type joints become possible with well-known theories $[2,3]$. This study conducted embedment loading tests on the resin-impregnated wood. The strengthening effect of the resin impregnated on the embedment properties was clarified using the results of the tests, and deformation was observed.

\section{Material and methods}

\section{Specimen preparation}

Air-dried Japanese cedar (Cryptomeria japonica D. Don), which is the most popular softwood species for construction in Japan, was selected as the test specimen. The authors prepared a large number of boards of Japanese cedar, with sizes of $20 \mathrm{~mm}$ in the radial direction, $105 \mathrm{~mm}$ in the tangential direction, and $200 \mathrm{~mm}$ in the longitudinal direction. The densities of each board were measured, and the boards were divided into six groups, so that there was less difference in the average density between the groups, as shown in Table 1. Groups N0 and N90 were the control groups, and the others were resinimpregnated groups.

For the resin-impregnated groups, a microscopic incision on the wood surface was created using an ultraviolet-wavelength short-pulsed laser. The square area of size $30 \times 30 \mathrm{~mm}$ at the center of the board surface (longitudinal-transverse plate) was decided as an incised area. A diode-pumped solid-state Q-switched laser (Talon355$15 \mathrm{SH}$, Spectra-Physics) was used for laser oscillation. The incision pattern was drawn using a Galvano scanner, as shown in Fig. 2. The hole density was $667 \mathrm{holes} / \mathrm{cm}^{2}$ and the target incision depth was $10 \mathrm{~mm}$, which is almost the maximum technical limit for creating the neat shape of

Table 1 Specimen groups used in this study

\begin{tabular}{|c|c|c|c|c|c|}
\hline Group & Resin & Loading direction & Number of specimens & Density $\left(\mathrm{kg} / \mathrm{m}^{3}\right)$ & $\begin{array}{l}\text { Implement } \\
\text { amount } I_{A}(\mathrm{~g} / \\
\left.\mathrm{m}^{3}\right)\end{array}$ \\
\hline NO & None & Parallel & 14 & $394 \pm 34$ & \\
\hline U0 & Urethane & Parallel & 17 & $393 \pm 34$ & $964 \pm 343$ \\
\hline $\mathrm{AO}$ & Acryl & Parallel & 20 & $392 \pm 37$ & $959 \pm 240$ \\
\hline N90 & None & Perpendicular & 16 & $392 \pm 32$ & \\
\hline U90 & Urethane & Perpendicular & 15 & $392 \pm 32$ & $944 \pm 417$ \\
\hline A90 & Acryl & Perpendicular & 14 & $388 \pm 26$ & $971 \pm 369$ \\
\hline
\end{tabular}




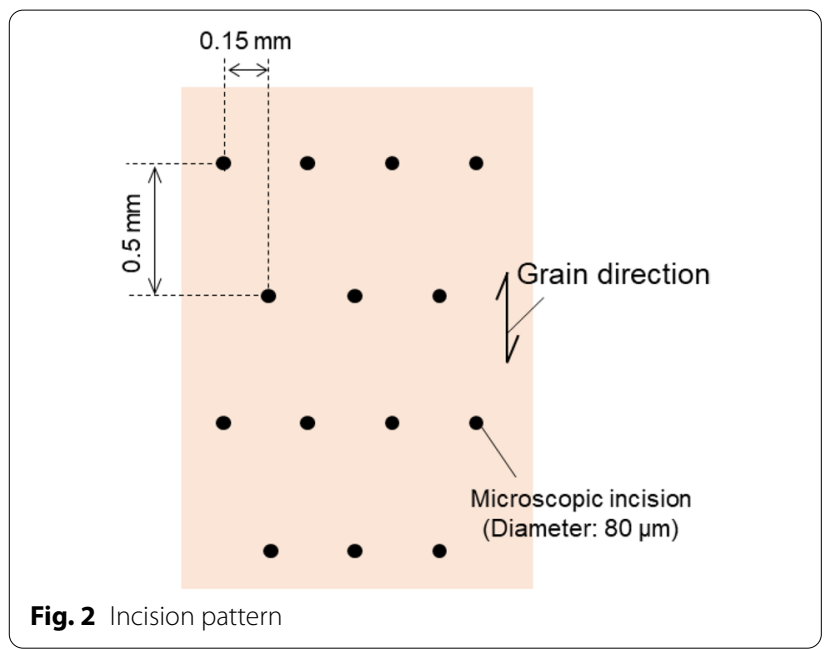

Table 2 Laser irradiation parameters

\begin{tabular}{ll}
\hline Wavelength $(\mathrm{nm})$ & 355 \\
Pulse width $(\mathrm{ns})$ & 25 \\
Pulse energy $(\mu \mathrm{J})$ & 260 \\
Pulse repetition rate $(\mathrm{kHz})$ & 50 \\
Power $(\mathrm{W})$ & 13 \\
Theoretical focal spot diameter $(\mu \mathrm{m})$ & 22.6 \\
Irradiation timber per 1 hole $(\mathrm{ms})$ & 20 \\
\hline
\end{tabular}

the microscopic incision. Although the thickness of the board was $20 \mathrm{~mm}$, the incisions were created from both the top and rear facings, such that the incisions pierced the board. Other laser irradiation parameters are shown in Table 2, and were determined according to previous studies $[12,13]$.

After creating the incisions, the wood board was impregnated with resin. In past, Fukuta et al. showed that resins with higher molecular weight may prevent swelling of wood cell wall and decreasing of strength [14]. Additionally, Fukuta et al. also tried using various types of commercial resins for surface hardening of wood [12]. Based on the results, two types of resin were chosen, which hardly decreased the mechanical property of cell wall due to swelling. The chosen resins were the same as in our previous study [13]. The first was a urethane prepolymer (PS-NY6, Kotobukikakou Co., Ltd.) (hereafter, urethane). The evaporation residue of urethane was $40 \%$. The urethane was impregnated into the incised areas using a paint brush. Because urethane is a coldsetting polymer, the wood board was left to stand for over 1 week after impregnation for curing. The second resin used herein was an acrylic monomer (DIAKITE PF-2730, Toeikasei Co., Ltd.) (hereafter, acryl). 0.6 parts by weight of $2.2^{\prime}$-azobisisobutyronitrile was included as a polymerization initiator. As in the case of urethane, it was applied using a paint brush. As acryl polymerizes in an anaerobic environment, a heating press machine was used with a temperature of $140{ }^{\circ} \mathrm{C}$ but with no pressure applied (i.e., the surface of the wood board only touched the heating plate of the machine). The heating time was approximately $30 \mathrm{~min}$.

The impregnation amount $I_{\mathrm{A}}$ was measured according to following equation:

$$
I_{\mathrm{A}}=\frac{m_{1}-m_{0}}{A \cdot d},
$$

where $m_{0}$ and $m_{1}$ are the masses of the wood boards before and after impregnation, respectively. $A$ is the area of the incised area $\left(900 \mathrm{~mm}^{2}\right)$, and $d$ is the incision depth (i.e., $20 \mathrm{~mm}$ ). Table 1 presents the average and standard deviation of the impregnation amount $I_{\mathrm{A}}$. As discussed in a previous study [13], $I_{\mathrm{A}}$ is strongly influenced by either the board as sapwood or heartwood. When dividing the board into six groups, the existing ratio of sapwood and heartwood was also considered, and there was almost no difference in $I_{\mathrm{A}}$ between the resin-impregnated groups, as presented in Table 1.

A bolt hole with a diameter of $12 \mathrm{~mm}$ was drilled at the center of the resin-impregnated area. Subsequently, the boards were cut such that half of the bolt holes remained. The board was cut along the cross-section for the specimens loaded parallel to the grain. The board was cut along the edge grain for specimens loaded perpendicular to the grain. The specimen size after cutting was $20 \times 105 \times 90 \mathrm{~mm}$ for the specimens loaded parallel to the grain and $20 \times 50 \times 200 \mathrm{~mm}$ for the specimens loaded perpendicular to the grain, as shown in Fig. 3.

\section{Testing method}

The embedment test was conducted according to ISO 10984-2 [15]. The testing setup is shown in Fig. 3. A round steel bar with a diameter of $12 \mathrm{~mm}$ and a smooth flank surface was mounted on the half-hole. A downward load was applied to the round steel bars. Thus, an embedment load was applied to the wood specimens. A constant loading of the ratio of $0.7 \mathrm{~mm} / \mathrm{min}$ was applied with the universal testing machine (AG-1 250kN, Shimadzu Co. Ltd.). The load was then measured using a load cell (SFL-50kNNAG, Shimadzu Co. Ltd.). Cantilever-type displacement gauges (CE-10, Tokyo Measuring Instruments Laboratory Co. Ltd.) were used to measure the relative displacement between the loading jig and top surface of the wood specimen as a deformation of the wood.

Characteristics were obtained according to ISO 10984-2 [15]. As shown in Fig. 4, the straight line (dotted line) was fitted using the least squares method for 


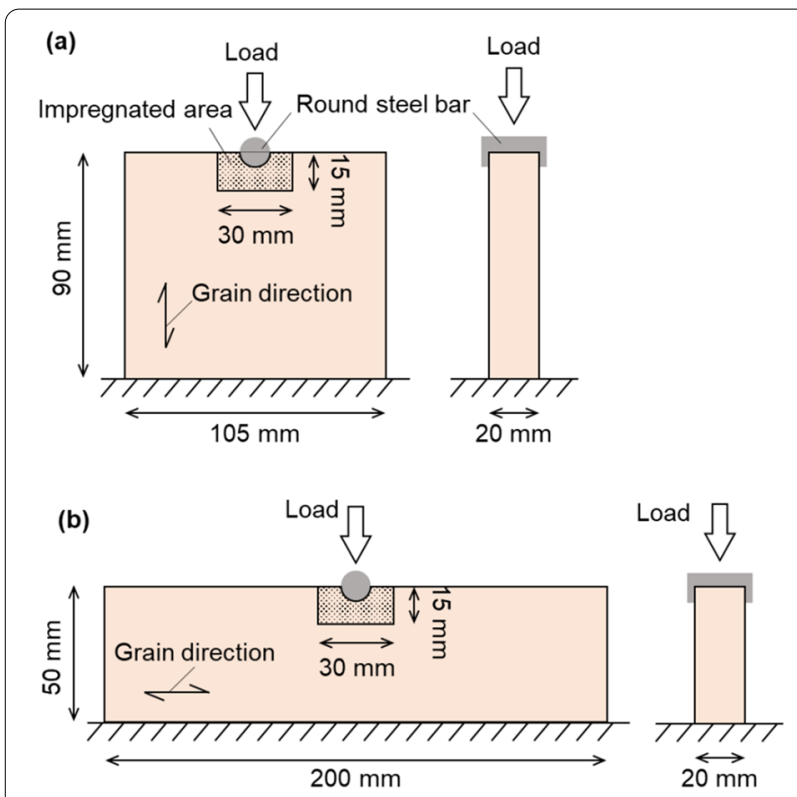

Fig. 3 Test specimens and experimental setups of embedment test. a Specimen loaded parallel to the grain. $\mathbf{b}$ Specimen loaded perpendicular to the grain

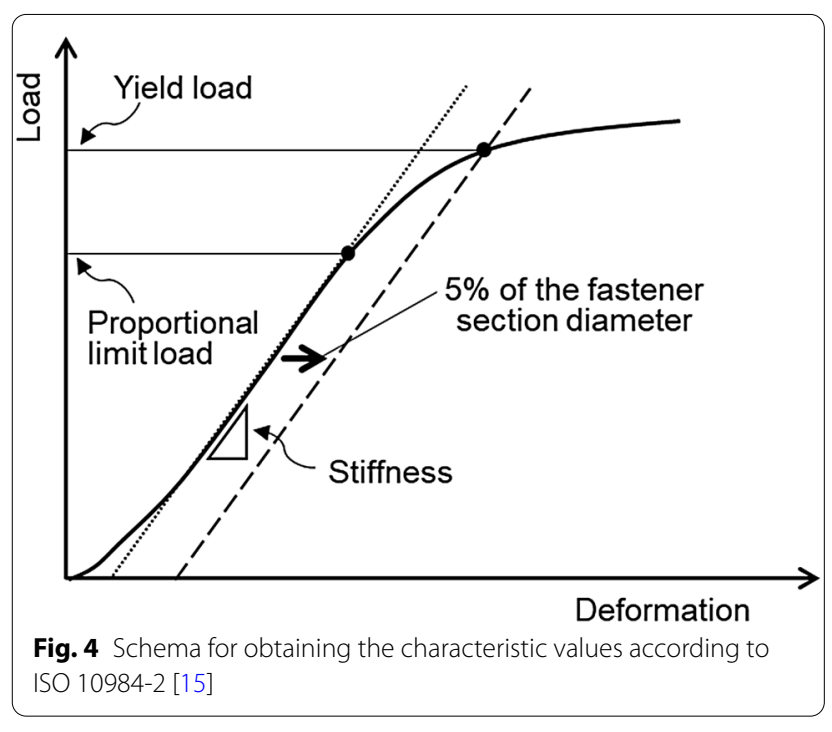

the visually linear part of the load-deformation relationship obtained by the test. In the most specimens, the linear part was selected as the data plots among 0.2-0.5 times the maximum measured load. Here, three characteristic values were obtained from the load-deformation relationship. Stiffness is the slope of the dotted line, and the proportional limit load is the value of the vertical axis at the point where the dotted line starts parting from the load-deformation relationship. The yield load is the value of the vertical axis at the intersection of the load-deformation relationship and the broken line, which is drawn by the translation of the dotted line. The length of the translation was determined as $5 \%$ of the fastener section diameter; therefore, the length in this study was $0.6 \mathrm{~mm}$.

\section{Results and discussion} Load-deformation relationship and visible failure mode The load-deformation relationships of the specimen loaded parallel to the grain are shown in Fig. 5a. The black lines are the result of the control specimen N0. At the beginning of the test, the load-deformation relationships increased linearly with the increment of deformation. When the load reached approximately $4-5 \mathrm{kN}$, the slope of the relationships started decreasing and a slight increment in load occurred until fracture. Figure $6 \mathrm{a}$ shows the specimen after the testing. A wrinkle was observed in the vicinity of the round steel bar. When the load rapidly decreased in the load-deformation relationship, a crack occurred from the bottom of the half-hole.

The red lines in Fig. 5a show the results for the urethane-impregnated specimens. As is evident from the graph, the red lines show the increment in their load at the beginning of the tests than the control specimens. At approximately 7-8 kN, the slope decreased in the relationship, and a fracture occurred at approximately $0.5 \mathrm{~mm}$ in deformation. During fracturing, a crack from the bottom of the half-hole occurred, as shown in Fig. 6b. In contrast to the control specimens, wrinkles in the vicinity of the round steel bar were not observed clearly. The blue lines in Fig. 5a show the results for the acrylimpregnated specimens. The slope at the beginning is higher than that of the control specimens and lower than that of the urethane-impregnated specimens. The acrylimpregnated specimens were fractured at approximately 1-2 $\mathrm{mm}$ in deformation, which means that the deformability was much higher than that of the urethane specimens. As shown in Fig. 6c, the wrinkle was also observed in the vicinity of the half-hole, which was similar with control group. Finally, a crack formed from the bottom of the half-hole. Although the acryl-impregnated group showed the higher deformability than that of urethane and similar failure mode, the reason was not clear. It may be influenced by the other factors than resin impregnation into wood cell (e.g., resin impregnation into cell wall, or bonding effect between cell wall and resin).

The results of the groups loaded perpendicular to the grain are shown in Fig. 5b. It should be noted that the loading was stopped at approximately $3 \mathrm{~mm}$ in deformation. This is not because of the fracture of the specimen, but the testing setup. The steel jig for loading, which the authors own, can fix the steel bar and avoid moving the bar during testing. However, the fixing part was 

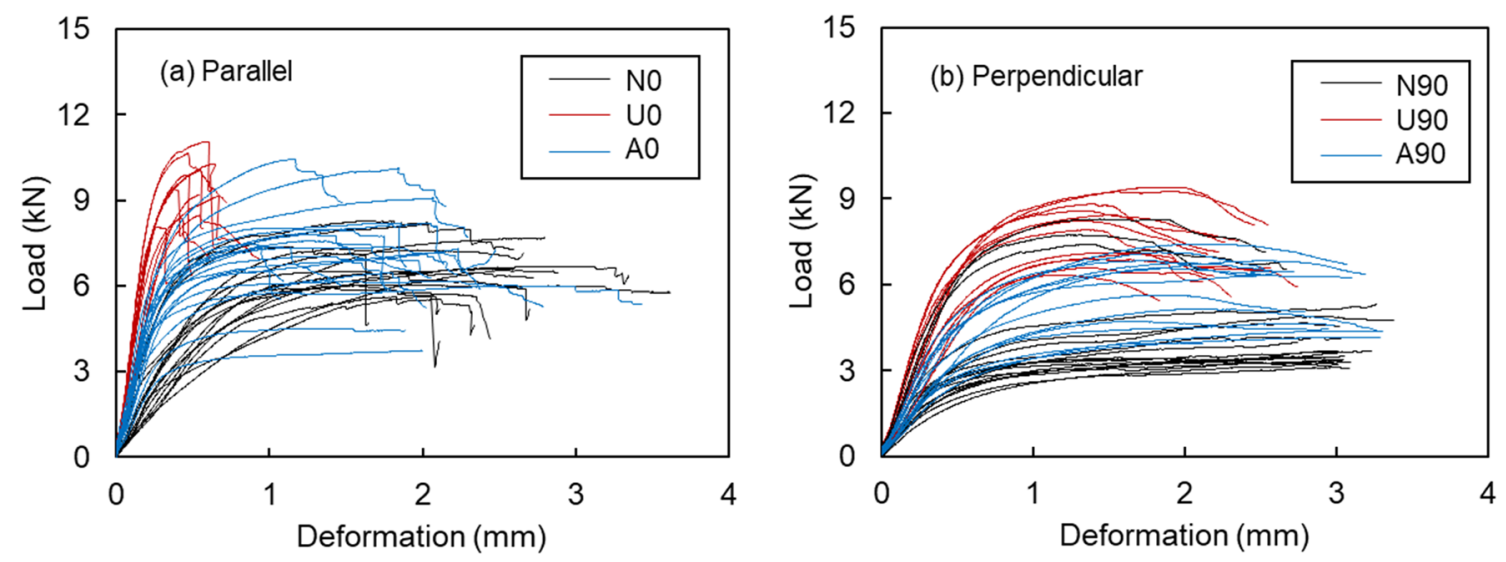

Fig. 5 Load-deformation relationships. a Specimen loaded parallel to the grain. $\mathbf{b}$ Specimen loaded perpendicular to the grain
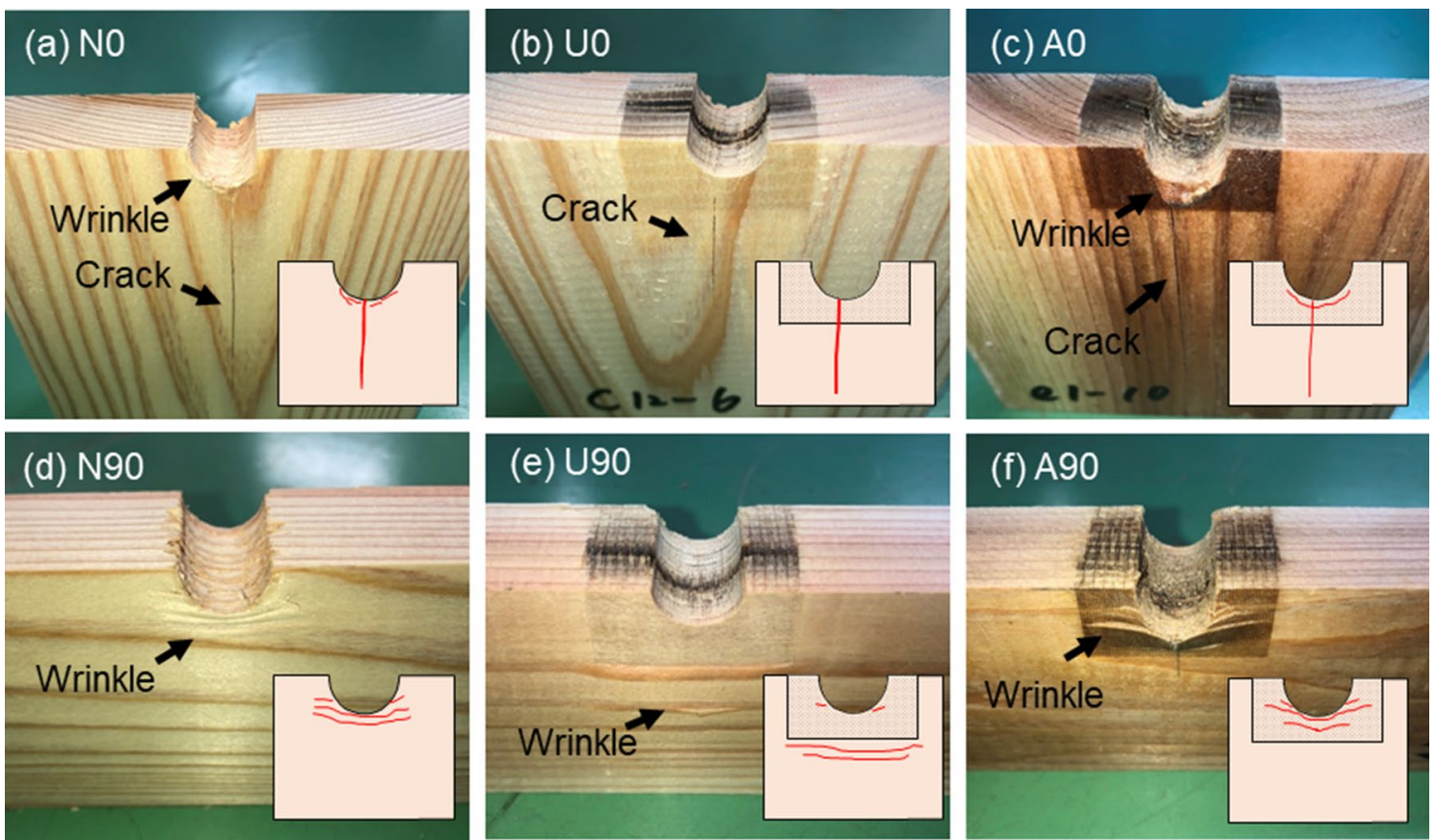

Fig. 6 Failure modes visually observed

in contact with the top surface of the wood specimens when the deformation reached approximately $3 \mathrm{~mm}$. As shown in the graph, there seems not to be a large problem for obtaining the characteristics according to Fig. 4 [15]; therefore, this paper discusses these load-deformation relationships. Similar to the results of groups loaded parallel to the grain, the urethane-impregnated specimen showed the highest load resistance among the three specimens. The acryl-impregnated specimen had a higher resistance than the control. In the specimens of the control and acryl-impregnated specimens, slight increments in the load were observed. If the loading continued, it was expected that the load increment would continue. However, in the urethane-impregnated specimen, a peak in the load was observed. This suggests that microcracks may occur near the steel bar at the maximum load. In the failure mode of the control specimen and the acryl-impregnated specimen (Fig. $6 \mathrm{~d}$ and f), a noticeable wrinkle was observed under the half-hole. In the urethane-impregnated specimen (Fig. 6e), wrinkles under the half-hole were less noticeable, and wrinkles appeared under the impregnated resin. 


\section{Characteristics}

The characteristic values obtained from the test are summarized in Table 3. It was revealed that the resin impregnation was effective for strengthening embedment properties. When comparing the average value of stiffness in the groups loaded parallel to the grain, the urethane-impregnated group U0 and acryl-impregnated group A0 showed 3.78 and 2.27 times those of control group N0, respectively. The strengths were also revealed to be proportional to the limit load; U0 and A0 showed 1.66 and 1.11 times that of N0, respectively. At the yield load, the value could not be obtained for the U0 group and some specimens of the A0 group. Their load-deformation relationships (Fig. 5a) lacked deformability; therefore, the broken line did not intersect with the load-deformation relationship. The authors tried to use the perfect elasto-plastic model as another authorized method, which replaces the load-deformation relationship with bi-linear composed of elastic line (proportional line starting from original point) and horizontal line starting from the end of the elastic line, to obtain the yield [16-19], but it failed because some specimens did not show the clear maximum load due to the testing setup.

Table 3 lists the characteristics of the groups loaded perpendicular to the grain. For example, the stiffness averages of the resin-impregnated groups U90 and A90 were 1.94 and 1.24 times those of control group N90, respectively. The proportional limit loads of U90 and A90 were 2.45 and 1.52 times those of N90, respectively, and the yield loads of U90 and A90 were 2.35 and 1.60 times those of N90.

As shown in Fig. 5 and Table 3, it is revealed the resin impregnation technique brings an improvement of embedment resistance, especially in stiffness. It is expected that the technique may contribute to develop the timber joint with high mechanical performance. Although the stiffness was significantly strengthened by resin impregnation, the lack of ductility is a serious

Table 3 Average and standard deviation of characteristic values obtained by the test

\begin{tabular}{lcll}
\hline Group & Stiffness $(\mathbf{k N} / \mathbf{m m})$ & $\begin{array}{l}\text { Proportional } \\
\text { limit load }(\mathbf{k N})\end{array}$ & Yield load (kN) \\
\hline N0 & $9.76 \pm 4.93$ & $4.60 \pm 0.53$ & $6.43 \pm 0.87$ \\
U0 & $36.88 \pm 7.87$ & $7.63 \pm 0.86$ & No data \\
A0 & $22.16 \pm 4.39$ & $5.09 \pm 1.03$ & $(7.01 \pm 1.60)$ \\
N90 & $7.38 \pm 2.06$ & $2.03 \pm 0.45$ & $3.28 \pm 0.52$ \\
U90 & $14.33 \pm 3.32$ & $4.98 \pm 0.89$ & $7.70 \pm 0.87$ \\
A90 & $9.18 \pm 2.28$ & $3.09 \pm 0.87$ & $5.25 \pm 1.20$
\end{tabular}

Yield load of group A0 can be obtain from 18 specimens out of 20 specimens problem. In the construction of resin-impregnated wood for dowel-type joints, additional reinforcement for improving ductility is necessary. Fortunately, the resin impregnation technique does not require any notch processing or size change; therefore, combination usage with other techniques is available. Past research has shown many techniques that contribute to improving the ductility $[8,9]$, and the combination use of these techniques seems to be effective for developing dowel-type timber joints with high mechanical properties.

Here, the authors touch on their previous research, which conducted a lateral loading test of bolted joints with resin-impregnated wood [13]. In the test, higher stiffness and yield loads were obtained in the acrylimpregnated specimen group than in the urethaneimpregnated group. According to the research, it was expected that the higher embedment characteristic values were shown in the acryl-impregnated group; however, the urethane-impregnated groups showed higher characteristics (Table 3), which was contrary to expectations. The reason for this is unclear, but the possible discussion is that acryl-impregnated specimens showed higher deformability in embedment, as shown in Fig. 5. When the lateral load acts on bolted joints, the embedment deformation is not uniform along the bolt direction. Even in the small range of slip in bolted joint, the local embedment deformation becomes large at a vicinity of contact part of members. In the case of the deformability is low, the decreasing of embedment resistance in local part may occur, and this may affect the appearance of higher lateral properties of bolted joints.

\section{Micro-level observation of failure mode}

The failure mode in the vicinity of the steel bar was observed using a SEM to clarify where the deformation occurred. A cube of $5 \times 5 \times 5 \mathrm{~mm}$ was removed from the specimen after the loading test, and the observed surface was smoothed with a microtome. Platinum was deposited on the smoothed surface under vacuum conditions, and the images were obtained using a SEM (JCM6000PLUS, JEOL Ltd.).

The SEM images are shown in Fig. 7. The illustrations at the lower left of each image indicate where the cube was removed from the specimens. Figure 7 a shows an SEM image of the control specimen loaded parallel to the grain. As shown by the white arrow, the wood cells in the vicinity of the steel bar were completely crushed and few pores remained. In contrast, the wood cells in the resinimpregnated specimens were less deformed, as shown in Fig. $7 \mathrm{~b}$ and $\mathrm{c}$. It was revealed that the inhibition of cell crushing was successful.

As described in section "Materials and methods", the evaporation residue of urethane is $40 \%$, and pores are 

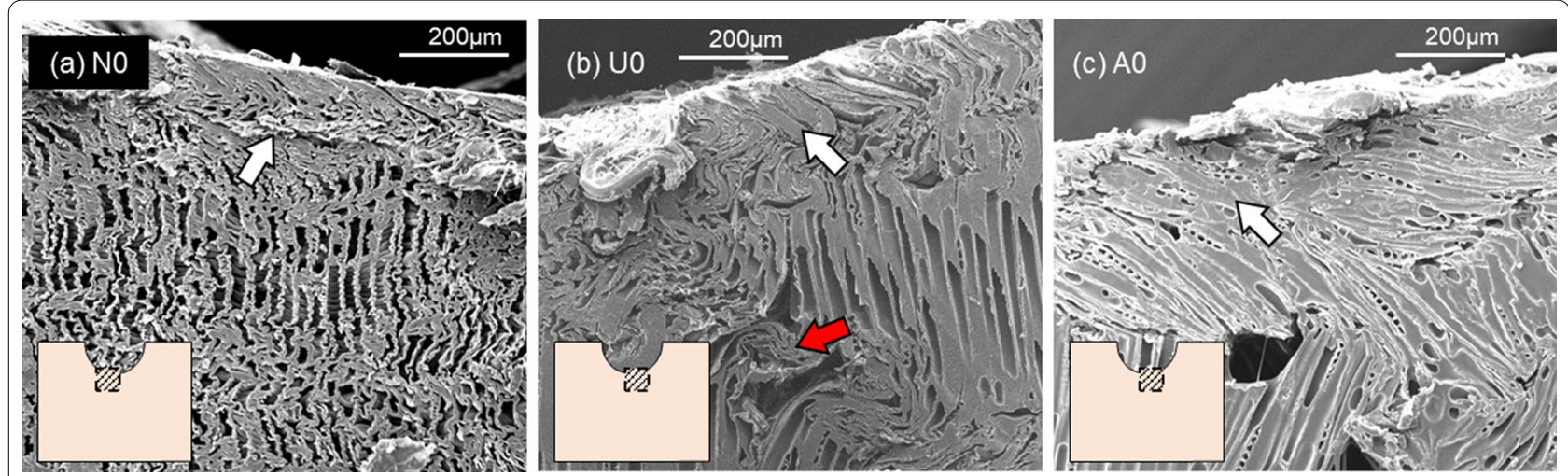

Fig. 7 SEM images for clarifying where the deformation occurred. The illustrations at the lower left on each image indicate where the cube was removed from the specimens. White arrows show the examples of the wood cells in the vicinity of the steel bar. Red arrow indicates the deformed part in urethane-impregnated specimens

formed when curing is completed. When the load acts on the urethane-impregnated specimen, deformation occurs at the pore, as indicated by the red arrow in Fig. 7b. Acryl-impregnated specimens had small pores. The wood cells were inclined under loading.

Although the resin in the cells was observed from SEM images, it was not possible to observe the resin filled into cell wall. The past research revealed that the swelling action of resin in the cell wall causes a decreasing of mechanical property [14], therefore, the clarification of the impregnating state of resin into cell wall and the effect on the mechanical properties become an important issue. Additionally, the resins used in this study were commercial ones. For obtaining the optimum properties of resin for strengthening embedment properties, the additional tests with various resin properties (e.g., various types, evaporation residue, or molecular weight of resin) are essential.

\section{Conclusion}

The authors conceived that if wood cells are fully filled before loading, the crushing of the cells can be inhibited, resulting in the strengthening of the embedment properties of the wood. In this study, two types of resins were impregnated into wood cells and their embedment properties were evaluated using a mechanical test.

The strengthening of the embedment properties by resin impregnation was clearly revealed. For the stiffness, higher values were obtained than the control specimens; the urethane- and acryl-impregnated group showed 3.78 and 2.27 times the stiffness values of the control groups in the parallel-loaded condition, and 1.94 and 1.24 times those of the control group in the perpendicularly loaded condition, respectively.
It should be noted that resin impregnation causes a lack of ductility. This is a serious problem in construction application. It is desirable that the resin impregnation technique is used in combination with other reinforcement techniques that contribute to improving ductility. For example, the attachment of other sheet material on the surface of wood block becomes one of the feasible combination techniques because the resin impregnation technique does not require any notch processing or size change.

\section{Abbreviations \\ $I_{A}:$ Impregnation amount; $m_{0}$ : Mass of the wood board before impregnation; $m_{1}$ : Mass of the wood board after impregnation; A: Area of the incised area; $d$ : Incision depth.}

\section{Acknowledgements}

This study is financially supported by Emachu Wood Promotion Foundation. The authors thank Ms. Sakurai and Mr. Morimoto, bachelor course students at Shizuoka University, for their great help in specimen preparation and test conduction.

\section{Authors' contributions}

KO designed and performed the experiments and analyzed the data. SF advised to decide the processing conditions. KO wrote the manuscript in consultation with SF and KK. All authors read and approve the final manuscript.

\section{Funding}

This study is financially supported by Emachu Wood Promotion Foundation.

\section{Availability of data and materials}

All data discussed during this study are included in this published article.

\section{Declarations}

\section{Competing interests}

The authors declare that they have no competing interests.

\section{Author details}

${ }^{1}$ College of Agriculture, Academic Institute, Shizuoka University, 836 Ohya, Suruga-ku, Shizuoka 422-8529, Japan. ${ }^{2}$ Aichi Center for Industry and Science Technology, 1261-1 Akiai, Yakusa, Toyota, Aichi 470-0356, Japan. 
Received: 21 October 2021 Accepted: 8 February 2022

Published online: 20 February 2022

\section{References}

1. Intergovernmental Panel on Climate Change (2014) Climate change 2014, mitigation of climate change. Fifth assessment report of the intergovernmental panel on climate change. Cambridge University Press, Cambridge

2. Kuenzi EW (1955) Theoretical design of a nailed or bolted joint under lateral load. Forest Products Laboratory Report: No. 1951

3. Johansen KW (1949) Theory of timber connections. Int Assoc Bridge Struct Eng 9(1949):249-262

4. Rodd PD, Guan ZW, Pope DJ (2002) Test results and modelling of a new timber connector. In: proc. of 7th world conference on timber engineering, Shah Alam, Malaysia. pp 160-167

5. Leijten AJM (1988) Densified veneer wood reinforced timber joints with expanded tuber fasteners. Dissertation, Delft University of Technology

6. Rodd PD, Leijten AJM (2003) High-performance dowel-type joints for timber structures. Prog Struct Eng Mater 5:77-89

7. Blass HJ, Schmid M, Litze B, Wagner B (2000) Nail plate reinforced joints with dowel-type fasteners. In: proc. of the world conference on timber engineering, BC, Canada, paper 8.6.4

8. Santos $C L$, Jesus AMP, Morais JJL, Fontoura BFC (2013) An experimental comparison of strengthening solutions for dowel-type wood connections. Const Build Mater 46:114-127

9. Lederer W, Bader TK, Unger G, Eberhardsteiner J (2016) Influence of different types of reinforcements on the embedment behavior of steel dowels in wood. Eur J Wood Prod 74:793-807

10. Tang L, Yang H, Crocetti R, Liu J, Shi B, Gustafsson PJ, Liu W (2020) Experimental and numerical investigations on the hybrid dowel and bonding steel plate joints for timber structures. Const Build Mater 265:120847

11. Namari S, Drosky L, Pudlits B, Haller P, Sotayo A, Bradley D, Mehra S, O'Ceallaigh C, Harte AM, Houjeyri IE, Oudjene M, Guan Z (2021) Mechanical properties of compressed wood. Const Build Mater 301:124269

12. Fukuta S, Nomura M, Ikeda T, Yoshizawa M, Yamasaki M, Sasaki Y (2018) UV-laser incision to apply wood-plastic compositions to wood surface. Mokuzai Gakkaishi 64:28-35 (in Japanese)

13. Ogawa K, Fukuta S, Kobayashi K (2020) Experimental study of lateral resistance of bolted joints using Japanese cedar (Cryptomeria japonica) treated with resin impregnation. J Wood Sci 66:71

14. Fukuta S, Watanabe A, Akahori Y, Makita A, Jmamura Y, Sasaki Y (2011) Bending properties of compressed wood impregnated with phenolic resin through drilled holes. Eur J Wood Prod 69:633-639

15. ISO 10984-2 (2009) Timber structures-dowel-type fasteners-part 2 : determination of embedding strength. International Organization for Standardization

16. Kawai N (2011) A standard test of timber joints. In: Architectural Institute of Japan (ed) Standard for structural design of timber structures. Maruzen Co. Ltd., Tokyo, pp 367-376 (in Japanese)

17. Wanyama OG, Sawata K, Hirai T, Koizumi A, Sasaki Y (2012) Effective lateral resistance of timber-plywood-timber joints connected with nails. J Wood Sci 58:315-321

18. Ogawa K, Sasaki Y, Yamasaki M (2015) Theoretical modeling and experimental study of Japanese "Watari-ago" joints. J Wood Sci 61:481-491

19. Ueda R, Sawata K, Takanashi R, Sasaki Y, Sasaki T (2020) Degradation of shear performance of screwed joints caused by wood decay. J Wood Sci $66: 42$

\section{Publisher's Note}

Springer Nature remains neutral with regard to jurisdictional claims in published maps and institutional affiliations. 